\title{
The Development of Tourism in the Low Carbon Economy
}

\author{
Wenhong Yang \\ School of Business, Qingdao Technological University \\ $11 \mathrm{Fu}$ Shun Street, Qingdao 266520, China \\ Tel: 86-532-8687-2256 E-mail: ywhlunwen@sina.com.cn
}

\begin{abstract}
Low-carbon economy has become an inevitable choice for the world's development. How to deal with the advent of low-carbon economy has become the tourism industry's concerns. This article explains the meaning of low-carbon economy, the relationship between the tourism and climate change, the reason that carbon emissions increase in the T\&T sector, and tourism development approaches in low-carbon economy.
\end{abstract}

Keywords: Low-carbon, Economy, Tourism, Climate

\section{Building a low carbon economy}

A Low-Carbon Economy (LCE) or Low-Fossil-Fuel Economy (LFFE) is a concept that refers to an economy which has a minimal output of greenhouse gas (GHG) emissions into the biosphere, but specifically refers to the greenhouse gas carbon dioxide. Recently, most of scientific and public opinion has come to the conclusion that there is such an accumulation of GHGs (especially $\mathrm{CO}_{2}$ ) in the atmosphere due to anthropogenic causes, that the climate is changing. The over-concentrations of these gases is producing global warming that affects long-term climate, with negative impacts on humanity in the foreseeable future. Globally implemented LCE's therefore, are proposed as a means to avoid catastrophic climate change, and as a precursor to the more advanced, zero-carbon society and renewable-energy economy. Some nations are low carbon-societies which are not heavily industrialized or populated. In order to avoid climate change at any point in the future, all nations considered carbon intensive societies and societies which are heavily populated, should become zero-carbon societies and economies.

As a fundamental venue to coordinate social and economic development, guarantee energy security and respond to climate change, development of low carbon economy is gradually gaining the needed consensus from more and more countries. Though without a fixed academic definition, the core of developing low carbon economy is to establish a development pathway that has high energy efficiency, low carbon consumption and low emissions. Under a fair and effective international climate regime, the efficiency of energy exploration, generation, transmission, transformation and use is expected to be increased greatly and energy consumption greatly reduced, so that the carbon intensity in energy supply for economic growth is dramatically reduced, so are the carbon emissions from energy consumption. Through increasing carbon sink and using CCS technology, the GHG emissions from fossil fuels that are hard to reduce can be offset. In the meanwhile, through the establishment of reasonable and fair technology transfer and financial support mechanisms, developing countries can undertake the costs to shift towards low carbon patterns while being at the lowest end of the value chain in the international trade structure. The perspectives of development value need to be changed in order to promote the transition of consumption towards a sustainable and low carbon future.

\section{Tourism and climate change}

Global warming of the climate system has become an unequivocal fact. According to a large amount of monitoring data, global average land surface temperature has risen 0.74 centigrade over the last century(1996 2005). And the rate of rising has been sped up. In the meantime, global average sea level has been constantly rising too. Our lifestyles, economies, health and social well-being are all affected by climate change, and although the consequences of climate change will vary on a regional basis, all nations and economic sectors will have to contend with the challenges of climate change through adaptation and mitigation. Tourism is no exception and in the decades ahead, climate change will become an increasingly pivotal issue affecting tourism development and management.

With its close connections to the environment and climate itself, tourism is considered to be a highly climate-sensitive economic sector similar to agriculture, insurance, energy, and transportation. The regional manifestations of climate change will be highly relevant for tourism destinations and tourists alike, requiring adaptation by all major tourism stakeholders. Indeed, climate change is not a remote future event for tourism, as the varied impacts of a changing climate are becoming evident at destinations around the world and climate change is already influencing decision-making in the tourism sector. 
At the same time, the tourism sector is a non-negligible contributor to climate change through GHG emissions derived especially from the transport and accommodation of tourists. Tourism must seek to significantly reduce its GHG emissions in accordance with the international community, which at the "Vienna Climate Change Talks 2007" recognized that global emissions of GHG need to peak in the next10-15 years and then be reduced to very low levels, well below half of levels in 2000 by mid-century." The tourism sector can not address the challenge of climate change in isolation, but must do so within the context of the broader international sustainable development agenda. The critical challenge before the global tourism sector is to develop a coherent energy use and GHG emissions, so as to allow tourism growth to simultaneously contribute to poverty alleviation and play a major role in achieving the United Nations Millennium Development Goals.

Tourism can play a significant role in addressing climate change if the innovativeness and resources of this vital global economic sector are fully mobilized and oriented towards this goal. The concern of the tourism community regarding the challenge of climate change has visibly increased over the last five years. The World Tourism organization and several partner organizations, including UNEP, convened the First International Conference on Climate Chang and Tourism in Djerba, Tunisia in 2003. This event was a watershed in terms of raising awareness about the implications of climate change within the international tourism community. The Djerba Declaration recognized the complex inter-linkages between the tourism sector and climate change and established a framework for future research and policy making on adaptation and mitigation. A number of individual tourism industry associations and businesses have also shown leadership on climate change, voluntarily adopting GHG emission reduction targets, engaging in public education campaigns on climate change and supporting government climate change legislation.

\section{The reason that carbon emissions increase in the $T \& T$ sector}

\subsection{Carbon emissions increase due to the tourism activities}

The UNWTO (United Nations World Tourism Organization) defines the Travel and Tourism (T\&T) sector as the activities of persons traveling to and staying in places outside their usual environment for not more than one consecutive year for leisure, business and other purposes not related to the exercise of an activity remunerated from within the place visited. When we travel, we have to use transportation and check in hotel, so it forms a tourism industry chain for travel services which including transportation, hotels, travel agencies, entertainment and retail etc. In this industry chain, each cluster contributes both direct and indirect carbon emissions. Carbon emissions from sources that are directly engaged in the economic activity of the T\&T sector are considered direct emissions. These are, for example, emissions from the usage of electricity by hotels and resorts and emissions from passenger aircrafts and railways. Indirect carbon emissions are produced as a consequence of the activity of the companies in the T\&T value chain, but occur from sources not directly engaged in the economic activity within the T\&T sector. For example, emissions from electricity usage in airline or travel agent offices, and emissions from transportation of hotel consumables, such as food or toiletries. According to the World Tourism Organization statistics, T\&T land transport (car, bus, rail) direct carbon emissions are forecast to grow at an annual rate of $2 \%$ per annum through 2035 . Air transport direct carbon emissions are estimated to grow at an annual rate of $2.7 \%$ per year, direct carbon emissions from ocean-going cruises are estimated to rise by $3.6 \%$ per year, Accommodation cluster carbon emissions are forecast to grow at 3.2\% per year.

\subsection{Carbon emissions increase due to poorly tourism management}

Many areas did not conduct further investigation and scientific plans in the tourism development. They over-exploited tourism resources, thus resulting in loss and waste of non-renewable tourism resources. In well known cultural treasures of Dunhuang Mogao Grottoes, because of too many tourists and high level of carbon dioxide in the air, many beautiful color buddhist carvings have changed, the intrinsic physical and chemical structure were also affected. At evergreen Xishuangbanna in Yunnan Province, in recent decades, too many tourist facilities such as hotels and restaurants have been constructed to expand tourism area for economic purposes, which deforested vigorously, thus leading to a sharp decline in forest area, the original sound ecological environment has been seriously damaged. Such examples are happened widespread in many scenic spots. In addition, some contractors use a series of product that waste resources for the sake of maximum profit in their business of restaurants, accommodation, entertainment. For example some hotels and restaurants waste resources by using disposable chopsticks. According to expert estimates, a 20 year old tree can only produce 3000 to 4000 pairs of disposable chopsticks, a 10 years old tree can only produce less than 10 million packs tissue paper, but the average daily absorption of carbon dioxide of a tree is about 5,023 grams, it was calculated that 1 hectare of forest can absorb carbon dioxide released by 200 person per day, and a tree also release a lot of oxygen. The destruction of forest resources may cause more carbon emissions. A medium hotel spending tens of 
thousands of small packing liquid shower, shampoo, toothpaste, disposable toothbrush per month, the pollution to the environment in the production of direct and indirect materials is far greater than the pollution induced by using of those disposable products itself.

\subsection{Carbon emissions increase due to misconduct of tourism consumption}

What influence and even undermine the tourism environment? It is china's large population, fast growing industry that lack of proper planning and management, and also lots of life waste brought by a large number of tourists for their poorly ecological awareness. The increase of emissions aggravated the air pollution, noise pollution and water pollution to the tourist reception. In scenic areas, sewage and garbage can be seen everywhere. Some tourists travel to some places, where can be seen ecological destruction and environmental pollution. They climb and touch historical sites at tourist spots. All of these make serious threat to the original style and lifetime of the monuments, and increase human destruction to the tourist attractions. Even a few tourists do hunting, gathering, camping and picnicking in tourism area, which not only increased the burden on the ecological tourist area, but also can cause species extinction. The balance of tourism area has been severely damaged.

\section{Measures of tourism development in low carbon economy}

\subsection{Scientific management of scenic}

In the development of scenic, it is necessary and reasonable to divide the tourist area into core area, buffer and experimental area. In planning of scenic, we need to apply ecological principles and methods to evaluate load capacity of the ecosystems and social systems of the tourist area. The scenic with limited environmental capacity must take measures to control the number of visitors. Specific action plans include: (1) tourism diversification: If possible, re-layout the strong attraction tourism area to distract tourist; Place entertainment at the edge of vacant block to attract tourists and reduce the pressure of the main tourist areas; determine the greatest day point of accommodation of each resource, if possible, limit the number of tourists; Plan the tourism line rational, and avoid the bottleneck effect. (2) queue management: Provide entertainment for tourist to enhance the overall experience when they queuing. (3) provides booking time: Limit visitors access to the major ecological sensitive spots through ticket sales during a specific time, but not other attractions. Eliminate the project that strongly affect the ecological environment, although those can bring profit in the short them.

\subsection{Reduce direct carbon emissions caused by the transport}

According to the Oslo Climate and Environmental Research Centre of International Studies, over the past 10 years, global carbon dioxide emissions increased by 13 percent, but the growth rate of carbon emissions from transport is $25 \%$. The release of the gas fuel which used by cars, ships, planes and trains and other modes of transport, is one of the factors that contribute to global warming. The tourism industry has very strong correlation with transport industry. According to the World Tourism Organization statistics, the carbon emissions caused by the use of transport for the tourism is $2 \%$ of the total global emissions. Therefore, we should reduce the carbon emissions caused by the transport for tourism. Specific practices including promoting public transport and hybrid vehicles, electric vehicles, bicycles and other low carbon or carbon-free ways. To this end, tourism area can also design some bike tours, and add some tourism projects. Meanwhile, tourism area can adopt as far as cable car and other environmental transport models to reduce carbon emissions. For example, the Shanghai World Expo makes use of new environmental friendly vehicles to achieve a zero carbon emissions. We can also learn from the practice of foreign airlines to implement carbon offset program. For example, Continental Airlines cooperation with non-profit organizations on sustainable development of international tourism has launched carbon offset program. The program is voluntary, allowing passengers know of carbon emissions caused by their travel route, and passengers can compensate to the international tourism organization according to their carbon emissions.

\subsection{Reduce energy consumption by promoting the green hotel development}

The hotel is an important part of the tourism industry. Currently, some hotels have already implemented some measures to reduce carbon emissions. For example, implementation of green hotels, but that is not enough, we need continue to implement and improve such operations. Specific practices include, (1) Enhance the green consumer advocacy. Hotel should treat guests as partners in environmental protection, initiative and promote environmental programs to hotel guests, and improve customer awareness of green consumption. (2) Develop green products, and guide to green consumer. Hotel should develop some green products, such as green rooms, green food, green services, and market them to customers actively, then guide customers to green consumer behavior. (3) Strengthen management to save energy. The hotel should start with the details of the management, 
pay attention to equipment maintenance and materials reuse. (4) Try for green certification. Green certification is the eco-label for hotel to implement green management, also is the means to establish green image and attract green guests. Hotels can trying for the certification from ISO14000, implement the "Green Globe 21" standards, thus promoting the hotel's management.

\subsection{Improve service quality by innovating tourism products}

As a leading tourism enterprise, travel agency should reduce the environmental costs of tourism by innovating tourism products and improving service quality. Specific practices include, (1) trying to avoid the carbon emissions factor in the design of tourist routes. As for some domestic tourist routes, try to choose transports with low carbon emissions. In the short distance air travel, carbon dioxide emissions released by passengers who take aircraft is about 3 times more than that released by passengers who take railways. Try to guide customers to check in green hotels, or carbon neutral hotel. (2) promoting the cultural connotation of tourism products. Promote the integration development of tourism and culture, sports, business and creative industries. (3) enhancing the training of tour guides. Increase their awareness of the important of low carbon travel, and guide the tourists to a low carbon travel. In the tourism process, as far as possible to avoid the fragile environmental areas, and communicate with local guides friendly.

\subsection{Change consumer's inappropriate behavior}

"Caring for the environment, low carbon travel," is not an empty slogan, but an embodiment of moral cultivation and environmental awareness of civic. Visitors should take practical action to care for nature. Try to take the means of low carbon travel, such as the use of bicycles, electric cars and public transport means in travel. In the tourist attractions, do not litter, and pollute water and soil, to prepare utensils to load garbage when travel to a special area; do not trample cherished plants consciously; Do not collect protected and endangered animal and plant samples; Use green tourism products. Conserve energy, and to be a low carbon tourist.

\section{References}

Achim Steiner. (2008). Cimate Change and Tourism. 2008 WTO\&UNEP.

Huang J P. (2000).Industrial energy use and structural change.Energy Economy.

Huixin Li.(2004). Eco-tourism carrying capacity and economic development of tourism.Frontier.

Per-Anders Enkvist.(2007).Acost curve for greenhouse gas reduction. The Mickincey Quarterly.

Thea Chiesa.(2009).Towards a low carbon travel \& tourism sector.World economic forum.

Zhijun Feng.(2009).Low carbon economy and scientific development.China Soft Science. 